\title{
Effects of Deceptive Advertising on Consumer Loyalty in Telecommunication Industry of Pakistan
}

\author{
Syed Akif Hasan,* Muhammad Imtiaz Subhani, Ana Mateen \\ Iqra University Research Centre, Iqra University, \\ *drsubhani@yahoo.co.uk
}

\begin{abstract}
This study is an attempt to interrogate the effects of deceptive advertising on consumer loyalty in telecommunication industry of Pakistan. Four variables, Call Charges (CC), Network Coverage (NC), Network Quality (NQ) and Customer Service (CS) were used to measure deception in Telecom Ads and then its effect on consumer loyalty while the consumer preference is used as the proxy of consumer loyalty. 10,000 random individuals from telecom industry were selected to conclude the results. Testing specification confirmed that the deception overwhelmingly exists in telecom ads and none of the telecom companies were providing exactly the same quality of service in terms of Call Charges, Network Coverage, Network Quality and Customer Service, as they promise in their advertisements, while, the consumers are inclined towards the services where the deceptions are seemingly meager.
\end{abstract}

Keywords: Advertising, Deceptive Advertising, Consumer Loyalty, Telecommunication

\section{Introduction}

Although the immense ventures and endeavors have been observed on deceptive advertising which includes identifying and measuring deception but a very slim focus is given on its effects on Consumer loyalty. Deceptive advertising is so to speak as the use of fake or deceptive statements in publicity (Campbell, 1995). Deceptive publicity has been around since the inauguration of time and is still common today. Sometimes it is done innocently by an advocate; however, it is done with the intent in the direction of deceiving the consumers (Aaker, 1974). Generally it is perceived that deception in advertising (false claims) leads to first purchase by the consumer, tricked by the false claims made by the marketer in advertising but eventually after the first use consumer realizes the real quality/ value of the product/ service in most cases and also explores the fallacy of the claims made by the marketer in advertisements. This realization of fallacy hinders the customer from being loyal to that particular brand. Since, a decade, the Telecommunication industry in Pakistan has undergone a drastic change and competition. For attracting consumers and to win the market share with the concept of optimized advertising expenditures, exaggerations have been the strategy to date of various players. Here, the objective of this study is to examine the effects of deceptive advertising on consumer loyalty specific to telecommunication industry of Pakistan.

\section{Literature Review}

Advertising: Advertising is defined as any paid form of promotion which paves the way for getting attentions of viewers for the subject (Boush, 1994). Advertising is a significant social phenomenon, which stimulates utilization, economic activity and life-styles (Urban, 2004). Nowadays, advertising is considered as a big business and is the main means of competing with other organizations. Furthermore, it is claimed that advertising provides information's to customers about the quality or the accessibility of numerous products. This is very imperative for customers so the time is saved that is consumed in searching the right product (Jerry, 1978).

Deceptive Advertising: Deceptive advertising or deceptive publicity is the use of fake or deceptive statements in publicity (Campbell, 1995). Deceptive publicity has been around since the inception of time and is still common today (Aaker, 1974). An advertisement or marketing is considered deceptive if it misleads the customers. The deceptive advertising can best be classed around three central figures which include fake advertising which is an absolute lie, false advertising which involves a claim- information discrepancy, such 
as not revealing all the conditions attached to a product/ products being advertised and deceptive advertising which involves a claim- faith interaction (Boush, 1994). The literature and many empirical evidence has confirmed that the advertisers and advocates of advertisers are always engaged and at times rigorously engaged in any/all of three stated categories of deceptions while campaigning for their products.

In the majority settings, measuring deceptive advertising requires detailed, far above the ground- incidence information (on ads, product quality, and inventories) that is difficult in the direction of survey (Boush, 1994).

Consumer Loyalty: The literature on advertising proposes that customer loyalty should be defined in two separate ways. The primary approach defines loyalty as the different feelings make an individual's overall affection towards a service, product, or organization which paves the way for intention to purchase. While, the subsequent approach of loyalty is behavioral (Urban, 2004). Examples of behavioral loyalty include continuing in the direction of purchase services from the same dealer which can also be phrased as the repeat purchase (Howard, 1974). Howard (1974) also confirms that satisfaction/loyalty relationship is path for the good managers in paying attention in customer behaviors connected to firm's performance.

The packages offered by the telecommunication companies are to deceive consumers and are targeted to limited market segmentation (Assael, 1998). The print and electronic forms of advertisements are under acted and the content is communicated to consumers in such a way that it seems to be generous and meaningful. The packages offered i.e. the call rates, SMS charges, connectivity charges, post and pre-paid connections are always taking up extra charges for just subscribing, which the customer doesn't realizes and have not much of awareness of this charged information, which eventually frustrates consumers and rattle the voice of brand switching.

\section{Hypotheses}

The following five relationships are hypothesized to study the deception in telecommunication ads and its effects:

H1: Service providers provide exactly the same call charges as they promise.

H2: Service providers provide exactly the same network coverage as they promise.

H3: Service providers provide exactly the same network quality as they promise.

H4: Service providers provide exactly the same customer service as they promise.

H5: Consumers mostly use that brand which has less deception than others.

\section{Methodology}

Sampling Method, Description of Data and Econometrical Methodology: A questionnaire was designed to conduct the survey and collect data from the mobile phone users regarding their usage pattern for the telecommunication services, while interrogating their views on the telecommunication advertisements, perception of deception in ads, and the effects of deception on their preference for telecommunication services. The data was collected through convenience based non-probability sampling from 10,000 mobile phone users using personal survey method. The collected data was analyzed through One-sample t-test and Test of Moments. The variables or the constructs which were used to gauge the deceptions in telecom ads include Call Charges, Network Coverage, Network Quality and Customer Service.

\section{Results and Discussions}

The empirical evidence which is extracted through the various consumers' perceptions portrays some very interesting findings to ponder as summarized in Table 1 and 2. The Table 1 explains the difference between the promised and provided coefficients of various measuring constructs of deceptions which include call charges, network coverage, network quality and customer services. 
The findings conclude that the entire outlined measuring constructs of deception significantly pave the way for establishing an overwhelming deceptions among consumers as the promised coefficients of these constructs significantly differ from the provided coefficients (i.e. The difference between the Promised and Provided Coefficients are significant at $\mathrm{p}<5 \%$ for all. Constructs used to measure Deceptions). It is also notable that the all of the telecom networks (firms) charge more call charges than they promise in their respective ads. Similarly Deceptions and exaggerations are also attributably present when the all outlined telecom network/ service providers talk about their network coverage, network quality, and customer service in their advertisements, as the coefficients of these constructs in terms of what telecom networks/ service providers provide is significantly lesser than the coefficients of what they promise.

Table 1: Testing Specifications of One Sample T-Test

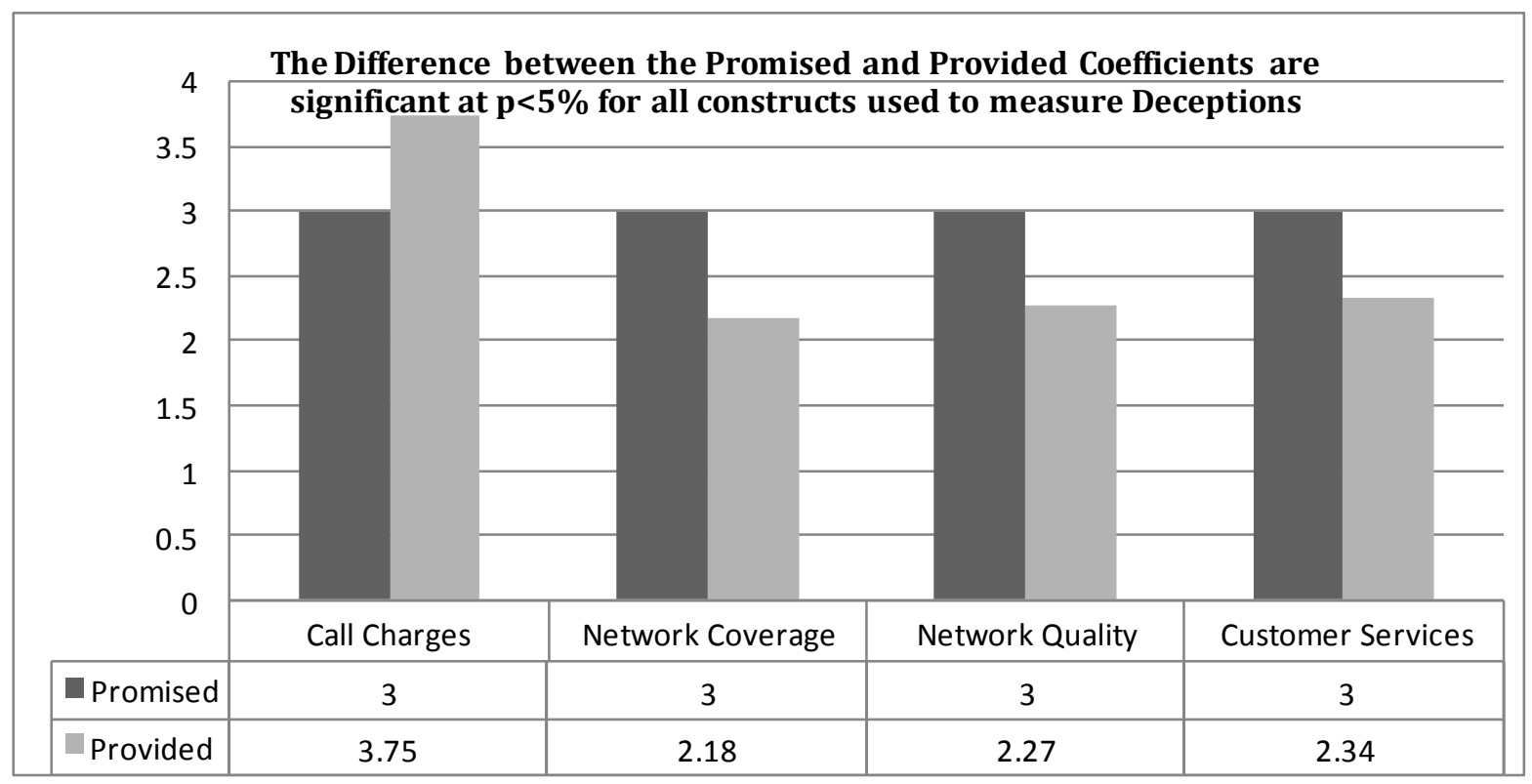

Table 2: Testing Specifications of Test of Moments

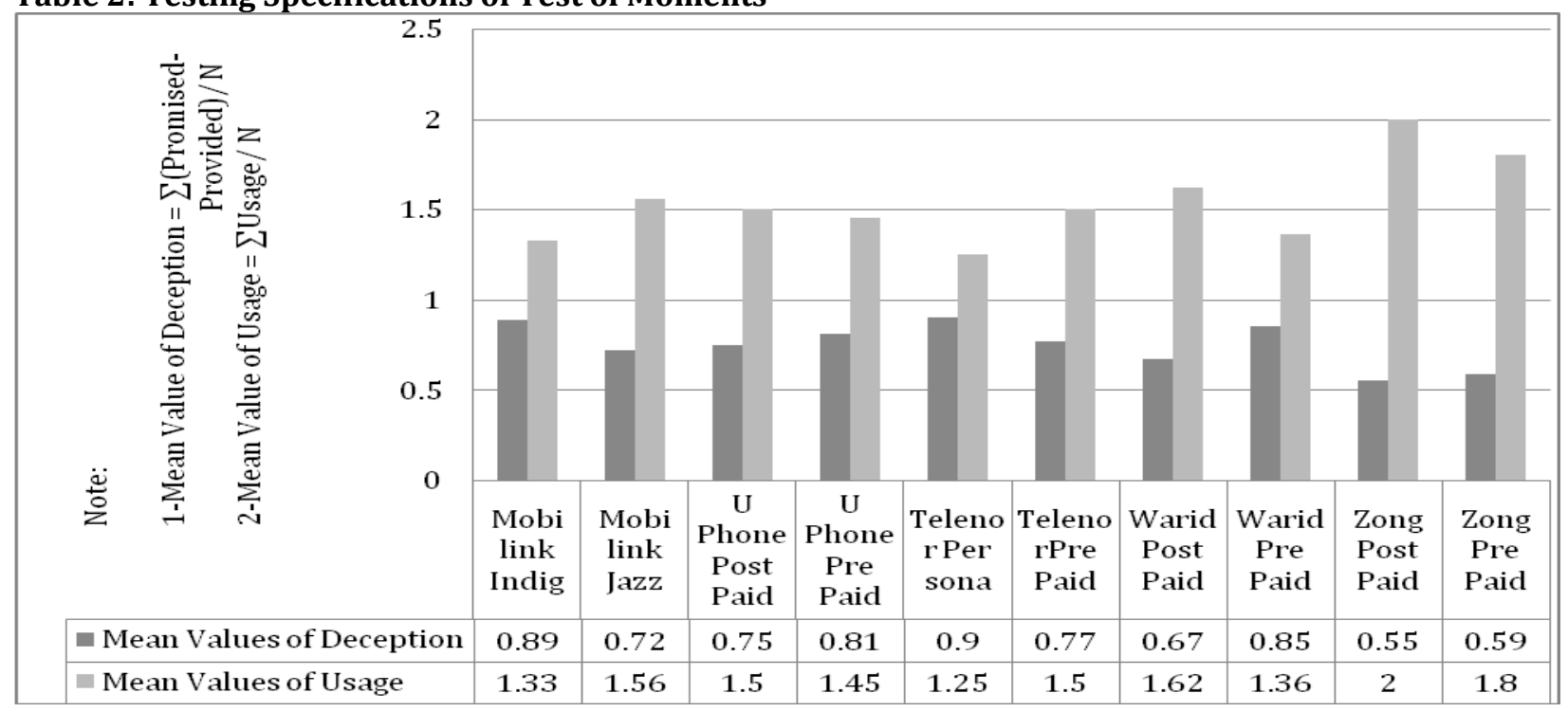


Thus, we fail to accept the first four hypotheses, as empirically, service providers don't provide the same call charges, network coverage, network quality and customer service as what they claim and promise. While the finding presented in table 2 further reveals that the customers/ consumers use those brands the most which has least deception as the Zong post paid has least deceptions in terms of all outlined constructs of deceptions than the other networks/ service providers and it has the most usage among consumers (i.e. mean value of deception $=0.55$; and mean value of usage $=2$ ), Therefore we fail to reject the fifth hypothesis.

\section{Conclusion and Recommendations}

Advertising deceptiveness is a controversial matter. Naturally, the advertiser's mostly avoid agreeing on whether a particular advertisement is deceptive (Gupta, 1988). While, the findings of this paper conclude and confirm that more or less every telecom network/ service provider is engaged in lifting false claims and exaggerations which is so to speak as deceptions when promoting and campaigning for their products. Moreover, in concluding this research, it has been apparent that the service providers', who mislead less to their users, always enjoy market shares more than those who exaggerate a lot. Thus, this study suggests that telecom companies should not focus on making false claims one after another but they should only ponder and focus upon rendering the level of competitive services to maximize their revenue generation. As one can see in this study that the Zong brand won and captured the market the most in less span of time with more reality-based advertisements.

\section{References}

Aaker, D. A. (1974). Deceptive advertising, Consumerism: Search for the consumer interest, Free Press: New York.

Assael, H. (1998). Consumer behavior and marketing in action, Cincinnati, OH: South-Western.

Boush, D. M. (1994). Adolescent skepticism toward TV advertising and knowledge of advertiser tactics. Journal of Consumer Research, 21, 165-175.

Campbell, M. C. (1995). When attention-getting advertising tactics elicit consumer inferences of manipulative intent: the importance of balancing benefits and investments. Journal of Consumer Psychology, 4, 222234.

Gupta, S. (1988). An Integrated Model of Inter-purchase Time, Brand Choice, and Purchase Quantity. Journal of Marketing Research, 25, 342-355.

Howard, J. A. (1974). The Dialogue That Might Have Happened, in Advertising and the Public Interest. American Marketing Association, 27-33.

Jerry, C. O. (1978). Cognitive Effects of Deceptive Advertising. Journal of Marketing Research, 15, 29-38.

Urban, G. L. (2004). The emerging era of customer advocacy. MIT Sloan Management Review, 45, 77-82. 